\title{
Reproductive ecology of short and long-term mating: implications for sexual selection and life history theory
}

\author{
Janko Međedović \\ Institute of criminological and sociological research, Belgrade, Serbia
}

(this is a preprint version of the manuscript, i.e. the manuscript is not yet peer reviewed)

\begin{abstract}
Mating patterns are crucial for understanding selection regimes in current populations and highly implicative for sexual selection and life history theory. However, empirical data on the relations between mating and fitness-related outcomes in contemporary humans are lacking. In the present research we examined the sexual selection on mating (with an emphasis on Bateman's third parameter - the association between mating and reproductive success) and life history dynamics of mating by examining the relations between mating patterns and a comprehensive set of variables which determine human reproductive ecology. We conducted two studies (Study 1: $\mathrm{N}=398, \mathrm{M}_{\mathrm{age}}=31.03$; Study 2: $\mathrm{N}=996, \mathrm{M}_{\mathrm{age}}=40.81$, the sample was representative for participants' sex, age, region, and settlement size). The findings from these studies were mutually congruent and complementary. In general, the data suggested that shortterm mating was unrelated or even negatively related to reproductive success. Conversely, longterm mating was positively associated with reproductive success and there were indices that the beneficial role of long-term mating is more pronounced in males, which is in accordance with Bateman's third principle. Observed age of first reproduction fully mediated the link between long-term mating and number of children but only in male participants. There were no clear indications of the position of the mating patterns in human life history trajectories; however, the obtained data suggested that long-term mating has some characteristics of fast life history dynamics. Findings are implicative for sexual selection and life history theory in humans.
\end{abstract}

Keywords: short-term mating; long-term mating; fitness; reproductive ecology; sexual selection; life history theory

\section{Introduction}

\section{1. Variations in human mating patterns}

Reproductive success is a central driver of natural selection and thus one of the main features of biological evolution itself. However, in order to reproduce, individuals must first mate - in many species this does not mean simply finding a partner for reproduction but courting, competing for a mate, retention of a mate, etc. Humans show high variability in their mating patterns. This is visible in marriage institutions where several forms of coupling are present, like monogamy, polygamy, polyandry, or polygynandry etc. According to the findings of the standard cross-cultural sample (SCCS) in most human societies polygamous relations are permitted, and monogamous populations are much rarer, with polyandry having the lowest frequency (Marlowe, 2000). Despite this basic finding, monogamy is the modal human mating system (Chapais, 2013) - the reason for this is the fact that a relatively smaller number of males have multiple partners even in polygamous societies (Wilson, Miller, \& Crouse, 2017). 
More generally than marriage systems, the variation in mating is present on a behavioral level as well. Individuals differ in their tendency to have long-term vs. short-term partner relationships, extra-pair mating, mate poaching, and mate guarding (Buss, 2006). Short and longterm mating were thought to be opposite poles of a singular dimension labeled sociosexuality higher levels of this behavioral tendency depict a tendency toward short term mating and uncommitted relationships (Simpson \& Gangestad, 1991). Empirical research showed that sociosexuality is more expressed in males compared to females, in many cultures (Schmitt, 2005). However, more recent research showed that short and long-term mating may not be the opposite poles of the single mating dimension but rather two distinct mating strategies with negative associations between them (Holtzman \& Senne, 2014; Jackson \& Kirkpatrick, 2007).

\section{2. Mating in the context of sexual selection}

There are at least two important theoretical frameworks that can help us understand the role of mating in fitness maximization. The first one is sexual selection. It is a specific case of natural selection which describes how inter and intra-sexual competition for mates can generate sex-specific mating patterns (Darwin, 1871). One of the main approaches to measuring sexual selection is based on the work of Bateman (1948; see also the recent review with the applications of Bateman's work to sexual selection in humans: Borgerhoff Mulder, in press). This framework posits that the sex which is more affected by sexual selection (most frequently these are males) should exhibit higher variation in mating, reproductive success, and higher covariation between mating and reproduction (Janicke, Häderer, Lajeunesse, \& Anthes, 2016). Consistent with these sex differences are the differences in parenting: the sex which is more affected by sexual selection tends to have lower parental investment (Trivers, 1972; see Kokko \& Jennions, 2008 and Jennions \& Kokko, 2015 for revising and expanding the basic ideas of Trivers).

Sexual selection is probably relatively weak in contemporary human populations: as stated before, the dominant pattern of marriage in humans is monogamy while sexual selection in monogamous populations is weaker than in polygamous (Moorad, Promislow, Smith, \& Wade, 2011). However, despite the magnitude of selection, the existing data show patterns which are congruent with Bateman's predictions. Males have higher variation in mating and reproduction success and more increased fitness by multiple mating in preindustrial Finnish populations (Courtiol, Pettay, Jokela, Rotkirch, \& Lummaa, 2012), early $20^{\text {th }}$ century US populations (Jokela, Rotkirch, Rickard, Pettay, \& Lummaa, 2010), and in rural natural-fertility populations in Tanzania (Borgerhoff Mulder \& Ross, 2019).

Evolutionary psychologists have not empirically analyzed Bateman's gradients directly. They have mostly focused on sex differences in mean levels of mating behavior with the data mostly confirming that males have higher sociosexuality levels than females (Penke \& Asendorpf, 2008; Schmitt, 2005). This suggests that males pursue short-term mating, engage in uncommitted relationships with greater frequency, and tend to have a higher number of sexual partners in general. However, this approach is criticized by stating that the mean levels of mating success in males and females should be the same on a population level (Bond, 2005). This is a consequence of Fisher's condition (Kokko \& Jennions, 2008) - the fact that copulation and reproduction demand two individuals of the opposite sex (since the main indicator of fitness is reproduction, we do not refer to homosexual partner relationships here). Hence, the findings of higher mean short-term mating success in males could be a consequence of the tendency of males to overestimate their number of sexual partners. Recent analysis of sex differences in mating 
showed that males and females are probably more similar than different in their mating patterns, with long-term mating being the dominant mating strategy (Stewart-Williams \& Thomas, 2013), which is in line with the data indicating a low magnitude of sexual selection in humans.

\section{3. What can mating patterns tell us about human life history?}

Another theoretical framework with tremendous impact in evolutionary human sciences is life history theory. In order to understand fitness maximization, it is not enough to analyze fitness proxies (i.e. reproductive success) but various fitness components and fitness-related outcomes. The reason is that fitness is a multi-component trait with its components constraining each other: e.g. investing in reproduction prevents investment in longevity (Tabatabaie, Atzmon, Rajpathak, Freeman, Barzilai, \& Crandall, 2011), offspring quantity is inversely related to offspring quality (Gillespie, Russell, \& Lummaa, 2008) and mating impedes parental investment (Gangestad \& Simpson, 2000). These are evolutionary tradeoffs - their existence forces individuals to generate different pathways towards fitness maximization; these pathways can be described as life history trajectories. Two basic life history pathways are labeled as fast and slow: the fast is oriented towards maximizing reproductive output with decreased longevity and longevity; the slow is characterized by the opposite pattern (Del Giudice, Gangestad, \& Kaplan, 2015). Life history trajectories are crucially dependent on the environmental characteristics: empirical data reliably show that harsh, unpredictable, hostile, and depriving environments are associated with fast life history trajectories (Chisholm, Quinlivan, Petersen, \& Coall, 2005; Dunkel, Mathes, Kesselring, Decker, \& Kelts, 2015; Griskevicius, Delton, Robertson, \& Tybur, 2011; Međedović, 2019; Sheppard, Pearce, \& Sear, 2016; Webster, Graber, Gesselman, Crosier, \& Schember, 2014).

Human behavioral ecologists rarely analyze mating patterns in a life history context; however, the research in evolutionary psychology provide some suggestions of human mating life history characteristics. In fact, there are two opposite hypotheses regarding the relations between mating strategies and environmental characteristics. The first can be labeled the developmentalattachment theory: harsh and stressful environments (Belsky, Steinberg, \& Draper, 1991) with elevated mortality rates (Chisholm, 1999) would lead to short-term mating strategies since they should be adaptive in such an environment. Quite oppositely, the strategic pluralism theory predicts that harsh, depriving, and hostile environments demands biparental care in order to elevate offspring fitness; hence, long-term mating patterns should be adaptive in these ecologies (Gangestad \& Simpson, 2000). Generally, the empirical data are mostly in line with the assumption that short-term mating is related to a fast life history since it is negatively related to life expectancy, with positive associations with family instability (Copping \& Campbell, 2015). Furthermore, short-mating patterns emerge from harsh and unpredictable community environments via earlier pubertal timing (Kogan, Cho, Simons, Allen, Beach, Simons, \& Gibbons, 2015). Congruent with these findings, long-term mating is positively associated with parental support (Lukaszewski, 2015) and negatively with family neglect and neighborhood crime (Chua, Lukaszewski, Grant, \& Sng, 2016). On the other hand, the data on the population level shows the opposite pattern - short term mating positively associates with beneficial ecological characteristics, which is congruent with the assumptions of the strategic pluralism theory (Schmitt, 2005). However, we have not been able to find data regarding the relations between short-term, long-term mating, and reproductive success or the other outcomes indicative for human reproductive ecology (e.g. age of first reproduction or having children with multiple partners). Hence, the role of mating patterns in life history dynamics is far from being resolved. 


\section{4. Goals of the present research}

Analyzing mating behavior is crucial for understanding how individuals and populations achieve and maximize fitness. It is relevant from the position of at least two theoretical frameworks in evolutionary sciences, sexual selection and life history theory, and it has important practical implications, for example in a demographical context (Borgerhoff Mulder, in press). However, the empirical data regarding the relations between mating and fitness are still very rare. In fact, we have not been able to find any data on the mating-fitness link in industrial and postindustrial populations, i.e. the populations which undergo a demographic transition. The main goal of the present research is to evaluate the links between mating and fitness in a wider context of human reproductive ecology, by measuring various outcomes which are significant for individual fitness (e.g. age at first reproduction, number of children and grandchildren, having offspring with multiple partners, etc). The data are analyzed and interpreted from the point of view of sexual selection and life history theory frameworks. These theories generate exact hypotheses regarding the relations between mating and fitness-related outcomes. In line with the sexual selection theory we calculated interactions between sex, mating, and fitness outcomes. Furthermore, we analyzed the relations between mating and other indicators of reproductive ecology in order to evaluate if there are patterns which are congruent with fast/slow life history dynamics.

In order to do this, we conducted two studies, with largely different samples. We measured mating by using the number of sexual partners and the duration of the longest relationship in every study. Usually, mating success is measured by the number of mating partners, especially the number of marriage partners in human behavioral ecological research. However, recently it has been argued that the time spent married is an important measure of mating success since it indicates opportunity for copulation and, consequently, reproduction (Blurton Jones, 2016; Borgerhoff Mulder, 2017; Borgerhoff Mulder \& Ross, 2019). However, the time spent in marriage may not be the ideal measure of partner relationship duration: in contemporary humans, especially in WEIRD societies (Western, Educated, Industrialized, Rich, and Democratic), there are many romantic partners who are not officially married, but despite this, form long-lasting partner relationships (Uggla \& Mace, 2017). Hence, we measured the longest partner relationship in general, regardless of whether it was an official marriage or not. In addition, we explored the total number of sexual partners; we address these two measures as the indicators of long and short-term mating, respectively. As has been recently addressed (Borgerhoff Mulder \& Ross, 2019), only by measuring these distinct indicators of mating can we obtain valid information on the role of mating patterns in human reproductive ecology. Hence, in the present research we tried to integrate evolutionary psychological and behavioral ecological approaches to mating into a single research framework.

\section{Study 1}

\section{1. Goals of the Study 1}

The main goal of Study 1 is to compare the psychometric measures of long and short-term mating with behavioral measures of mating. We aimed to analyze the convergence of these measures and the relations between mating, ecological variables, and reproductive outcomes. We 
expected positive correlations between the short-term mating scale and the number of sexual partners and between the long-term mating scale and the duration of the longest relationship. Furthermore, we expected higher associations between mating and reproductive success for males as predicted by the sexual selection theory. Finally, if short-term mating is related to fast life history dynamics, this mating strategy should be related to a harsher environment, earlier reproduction, a higher number of children, and a higher number of desired children.

\section{2. Method}

\section{2. 1. Sample}

The data were gathered by an on-line study. Students of the evolutionary social science course from the Singidunum university of Belgrade disseminated the link for the on-line survey via social networks and e-mails to informal contacts as a part of their course. They asked the initial participants to find additional participants so the sampling was conducted via the snowballing technique. The purpose of the study and the informed consent form was present on the first page of the survey. This procedure resulted in a convenience sample of 398 individuals of Serbian ethnicity ( $68 \%$ females; $\left.\mathrm{M}_{\mathrm{age}}=31.03[\mathrm{SD}=11.65]\right)$. The participants' education was higher than average: the majority of participants have finished college (44\%) or they were attending college at the time of data gathering (43\%) with a lower number of participants who finished high school (13\%). The majority of participants did not have children (75\%). Participation in the research was voluntary for all participants.

\section{2. 2. Measures}

We measured short and long-term mating using the behavioral and psychometric measures. The former ones are operationalized as the Number of sexual partners and the Duration of longest (partner) relationship (expressed in months), respectively. Psychometric measures were operationalized via the items from short and long-term mating scales of the expanded sociosexuality inventory (Jackson \& Kirkpatrick, 2007). Every scale was measured via 5 items with the standard Likert-type scale for responding (items which were used in the present study can be seen in the Supplementary material).

In addition, we measured self-reported socio-economic status in childhood (Childhood SES) and Relations in family: 1) On a scale of 1 to 10, please evaluate the financial situation in your family while growing up"; 2) "On a scale of 1 to 10 , please evaluate the relationships in your family while growing up", respectively. Number 1 was marked "Very bad" while 10 represented "Very good". We also measured the Age of first sex with the following question: "How old were you when you had your first sexual intercourse?" Reproductive success was measured via the number of biological children. The age at first reproduction was measured via two items: participants who had children were asked "How old were you when you had your first child?" We refer to this variable as the Observed age of first reproduction. If a participant did not have children, the question was: "When would you want to have your first child? Please indicate the age you would like to have your first child". This variable is labeled as Planned age of first reproduction. Finally, we asked participants what their total Desired number of children is.

\section{3. Results}




\section{3. 1. Sex differences and correlations between the examined variables}

First, we show sex differences in the examined variables, including the tests for differences in means and variances. These data are shown in Table 1. We can see that males had higher mean scores on both measures of short-term mating, Planned age at first reproduction, and Childhood SES; furthermore, they reported lower values of psychometrically measured Longterm mating. Males also had higher variation in the Number of sexual partners and Long-term mating.

- Table 1 about here -

Afterwards we calculated the correlations between the examined variables on the entire sample (we calculated both zero-order correlations and partial correlations controlled for participants' sex, age, and education; the correlations in males and females separately are shown in the Supplementary material). These data are presented in Table 2.

\section{- Table 2 about here -}

Since the participants' sex, education, and especially age are crucial covariates in the examined relations, we interpreted only partial associations. The Number of sexual partners correlated positively with Short-term mating and the Observed age of first reproduction; it was associated negatively with the Age of first sex. Short-term mating had positive correlations with Childhood SES and the Planned age of first reproduction, while it had negative associations with the Age of first sex. Relationship duration correlated positively with Reproductive success and negatively with the Age of first sex. Finally, Long-term mating had negative associations with the Planned age of first reproduction and positive with the Desired number of children. Note that the Longest relationship duration was not related to Long-term mating. Most of the significant correlations had small to moderate effect sizes.

\section{3. 2. Sex as the moderator of the mating-fitness link}

We conducted a regression analysis where we set the participants' sex, age, education, and mating patterns as the predictor variables; reproductive success was set as the criteria measure. This procedure resulted in a statistically significant regression model with participants' age, education, and Longest relationship duration as significant predictors. Afterwards, we added the interactions between sex and mating at the second level of the analysis. One interaction showed to be significant: Males with longer relationships had elevated Reproductive success, compared to females. Contributions of the variables to the regression functions and graphic representations of the interactions can be seen in Table 3 and Figure 1.

- Table 3 and Figure 1 about here -

\section{4. Discussion}


Sex differences in mating obtained in Study 1 are partially in accordance with the previous results. Both indicators of short-term mating were more expressed in males - which is the finding observed in various cultures (Schmitt, 2005). However, in contrast to the previous research (Jackson \& Kirkpatrick, 2007) we obtained that females had higher mean levels of attitudes towards long-term relationships (but not mean levels of longest relationships); furthermore, previous research (Jackson \& Kirkpatrick, 2007) found negative relations between psychometric operationalizations of short-and long term mating - but we did not detect associations between these measures. Males and females also differed in variation of sexual partners they had and scores on the scale of long-term mating: variation on both variables was higher in males. This is in accordance with Bateman's first principle (Bateman, 1948) that variance in mating should be higher in the sex which is more affected by sexual selection - in humans, as in the majority of species, these should be males (Borgerhoff Mulder, in press). However, note that we did not confirm Bateman's second observation - reproduction success did not variate in males more than in females. The absence of the effect may be due to the relatively small subsample of participants who had children in the present study.

Individuals with longer relationships had a higher number of children - this relationship was statistically significant even when participants' sex, age, and education were controlled for in analysis. This is a confirmation of the finding that a higher amount of time spent married is beneficial for fitness (Borgerhoff Mulder \& Ross, 2019). Furthermore, long term mating elevated fitness especially in males. Previous research also established that mating increases fitness in males more than in females (Courtiol et al., 2012; Jokela et al., 2010), with only one study which showed that long-term, but not short-term mating contributes to male fitness (Borgerhoff Mulder \& Ross, 2019). This finding confirms Bateman's third principle that the association between mating and reproduction should be higher in males.

The analysis of mating patterns in the life history context provided inconclusive results. Generally, different mating patterns showed indications of both fast and slow life history. Both indicators of short-term mating showed negative relations with the onset of sexual behavior which may indicate fast life history; however, the number of sexual partners showed positive associations with the observed age of first reproduction, while psychometrically measured shortterm mating had positive relations with childhood SES and the planned timing of reproduction, which indicates slow life history. Long-term mating had a more unambiguous position in life history dynamics. Relationship duration had a negative relation with sexual debut and positive with the number of children; psychometrically measured long-term mating negatively correlated with planned reproduction timing and positively with total expected fertility. The pattern of associations suggests that both indicators of long-term mating are associated with fast life history. This pattern of associations is more congruent to the strategic pluralism theory (Gangestad \& Simpson, 2000), but only indirectly since long-term mating did not positively associate with a harsh environment as predicted by this theory. However, these findings suggest that long-term, in contrast to short-term mating, is more involved with maximizing reproductive output which is the central indicator of fast life history trajectories (Del Giudice et al., 2015).

Finally, the number of sexual partners was significantly related to the attitudes toward short-term mating which was obtained in previous research as well (Jackson \& Kirkpatrick, 2007; Kruger, 2017). However, the duration of the longest relationship was not associated with attitudes toward long-term relationships. This clearly shows the discrepancy between attitudes and behavior - people may want to be committed in long-term romantic relationships, but for various reasons they fail to execute this intent in their behavior. This finding, combined with markedly 
different relations between psychometrically and behaviorally measured mating patterns and other variables, suggests that these measures do not assess the same concepts. Since we are primarily interested in behaviors, not psychological representations of mating, in further studies we administered only the behavioral indicators of mating.

\section{Study 2}

\section{1. Goals of Study 2}

In Study 2 we wanted to further explore the relations between mating, environment and reproductive outcomes. Furthermore, the characteristics of the sample (larger sample size and variation in age) allowed us to investigate additional parameters of reproductive ecology like the number of children and grandchildren and having children with different partners. The analytic plan is very similar to Study 1 - analyzing the relations between all variables and the moderation of participants' sex in the mating-fitness link. However, an additional hypothesis is tested in this study - since Study 1 findings suggested that the age of first reproduction may be a mediator in the mating-fitness link, we tested this hypothesis as well using path analysis. The assumed fast life history dynamics based on reproductive ecological variables used in the present study should be reflected in elevated environmental harshness, higher reproductive success and higher probability of having children with different partners followed by an earlier age of first reproduction.

\section{2. Method}

\section{2. 1. Sample}

The sample was collected through the on-line panel of Deep-Dive, a market research company in Serbia. Potential participants were selected from a database of respondents who are registered as interested to participate in research. Participants were motivated by a voucher that can be used in certain stores. The sample was representative of the general population in terms of the participants' sex, age, region, and settlement size (quota were made according to the 2011 census). A total of 996 subjects ( $52 \%$ females) participated in the study. They were aged 18 to 81 $(\mathrm{M}=40.81, \mathrm{SD}=12.78)$. The distribution of the participants' education was as following: uncompleted elementary school: $0.4 \%$; completed elementary school: $1.2 \%$; completed secondary vocational school: 40.8\%; completed gymnasium: 9.2\%; and completed college: 48\%. The measures analyzed in the present report were administered as part of a larger survey, and the sample itself is related to our previously published report (blinded for review).

\section{2. 2. Measures}

Number of sexual partners, Longest relationship duration, Childhood SES, Relations in family, Number of children, Age of first reproduction (both planned and observed) were measured exactly as in Study 1. In addition, we asked the participants for the number of their grandchildren and if they had children with multiple partners. 


\section{3. Results}

\section{3. 1. Sex differences and the correlations between the examined measures}

First, we show the differences between males and females on analyzed measures (Table 4). The findings showed a clear pattern: males had both higher variation and mean scores on the Number of sexual partners, Longest relationship, Age of first reproduction (males had higher means on both planned and observed Age of first reproduction but the variation was significantly different only on the former measure), Number of children and grandchildren, and Children with different partners. Bivariate associations between the analyzed measures are shown in Table 5 (the correlations in males and females separately are shown in the Supplementary material). The Number of sexual partners was negatively associated to the Number of children while the Longest relationship was positively associated with this fitness criterion and negatively with the Observed age of first reproduction (note that we interpreted only the correlations partialized for participants' sex, age, and education, similarly as in Study 1).

- Table 4 and 5 about here -

\section{3. 2. Moderators in the mating-fitness link}

We ran regression models for the Number of children and grandchildren as the criteria variables; participants' sex, age, education, and mating patterns were set as the predictors. Participants' age and Longest relationship had positive contributions to the prediction of the Number of children, while education had negative contributions to the regression function (Table 6). We tested the interactions between sex and mating in the prediction of this criterion as well; however, we did not detect significant interactions.

The Number of grandchildren was predicted with the inclusion of the Number of children in the predictors set since it is a crucial covariate when analyzing the variation in the number of grand-offspring. Participants' age, Longest relationship, and the Number of children positively predicted this criterion. Furthermore, we found one significant interaction: Males with longer relationships had more grandchildren, compared to females (Table 6, Figure 2).

- $\quad$ Table 6 and Figure 2 about here -

\section{3. 3. Age of first reproduction as the mediator between mating and fitness}

Finally, we conducted multigroup path analysis (for males and females separately) where we set short and long-term mating as the predictors, the Observed age of first reproduction as the mediator, and fitness indicators (Number of children and grandchildren) as criteria variables (thus, the path analysis is performed only on participants who have children). All variables were modelled as observed ones. Note that we included age and education in the analysis as well; however, we do not show these variables in the model in order to save space. Comparisons between males and females showed significant differences in analyzed paths between the groups $\left(\chi^{2}(18)=56.85 ; \mathrm{p}<.001\right)$. Hence, we calculated path coefficients from subsamples of males $\left(\chi^{2}(3)=1.234 ; \mathrm{p}>.05 ; \mathrm{NFI}=.998 ; \mathrm{CFI}=1.000 ; \mathrm{RMSEA}=.000\right)$ and females $\left(\chi^{2}(3)=4.256 ; \mathrm{p}>.05\right.$; $\mathrm{NFI}=.992$; $\mathrm{CFI}=.998$; RMSEA=.028) separately and showed them on Figure 3 . In general, the 
Observed age of first reproduction fully mediates the links between Long term mating and number of children, but only in males (standardized indirect effect: $\beta=.05 ; \mathrm{p}<.01$ ). We tested the indirect effect of Long term mating on the Number of grandchildren as well, but this effect did not reach statistical significance (standardized indirect effect: $\beta=.03 ; p=.10$ ). The link between Longest relationship and Observed age of first reproduction was not statistically significant in females; however in this subsample there was a direct positive effect of Longest relationships on Number of children. These data are showed in Figure 3.

- Figure 3 about here -

\section{4. Discussion}

The strong point of Study 2 is certainly the size of its sample and even more the fact that the sample was representative of at least some characteristics like sex, age, region, and settlement size (but not participants' education). In light of this it should be noted that all three of Bateman's observations were confirmed in this study: males had higher variance both in mating (the number of partners and relationship duration) and reproductive success (the number of children, grandchildren and children with multiple partners), together with a higher association between long-term mating and the number of grandchildren as a marker of fitness. In accordance with previous data, findings showed that long-term mating is more beneficial for fitness, especially for males (Borgerhoff Mulder \& Ross, 2019). Generally, the data are in accordance with the theoretical expectations and previous findings (Brown, Laland, \& Borgerhoff Mulder, 2009; Courtiol et al., 2012; Jokela et al., 2010; Moorad et al., 2011) that human males are more affected by sexual selection. However, it should be noted that only long-term mating was positively associated with fitness - in fact, multivariate analysis showed that short-term mating was negatively related to the participants' number of children. The crucial reproductive event which mediates these links between short, long-term mating and fitness is reproductive timing. Individuals in long-term relationships have earlier first reproduction; since the age of first reproduction is reliably inversely related to total reproductive success (Sanjak, Sidorenko, Robinson, Thornton, \& Visscher, 2018; Tropf, Stulp, Barban, Visscher, Yang, Snieder, \& Mills, 2015), this provides these individuals with higher fitness. The opposite stands for short-term relationships.

Similarly to the previous study, the data more clearly indicate that long-term mating is involved in fast life history dynamics: in contrast to the number of sexual partners, longer relationships are associated with maximizing reproductive output. The results from the existing research thus indirectly supported the strategic pluralism theory (Gangestad \& Simpson, 2000) while they opposed developmental-attachment theory (Belsky et al., 1991) which suggested a fast life history role of short-term mating (Chua et al., 2016; Kogan et al., 2015; Lukaszewski, 2015).

\section{General discussion}

Variation in mating behavior is certainly one of the crucial determinants of variance in fitness itself. Mating is a prerequisite for reproduction, but the implications of mating may go even further and affect other fitness components like having offspring with multiple partners, parental investment etc. Interestingly, the empirical data on the associations between mating and reproduction as a prerequisite for sexual selection (if more highly expressed in one sex) are 
surprisingly lacking, especially in industrial and postindustrial human populations. This topic is of high importance, not only from the viewpoint of sexual selection, but life history theory in humans as well, together with the potential demographic implications. In order to explore the role of mating in reproductive ecology we conducted two studies with samples which differ in important reproductive characteristics and assessing different outcomes related to the environment and reproductive events. Despite the large differences between the samples the results were relatively congruent: 1) long-term mating turned out to be beneficial to fitness, while in contrast, short-term mating was either non-associated or even negatively associated to fitness; 2) long-term mating showed enhanced adaptive benefits for males compared to females; 3 ) age of first reproduction was the crucial mediating variable in the link between long-term mating and fitness in males; 4) short and long-term mating did not show unambiguous life history dynamics in the context of the fast/slow continuum; however, the obtained findings suggested that longterm mating had more consistent associations with fast life history dynamics. The data show promising potential in understanding the reproductive ecology of mating in post-industrial humans as well as patterns of sexual selection in contemporary human populations.

\section{1. Sexual selection on mating}

Present findings revealed crucial differences in short and long-term mating regarding their relations with fitness: long-term mating showed more positive associations with fitness compared to short-term mating, where no relations or even negative relations with fitness were observed. In Study 1, long-term mating was positively associated with reproductive success (although only in males) and the total desired number of children; it was positively associated both with the number of children and grandchildren in Study 2. In both studies, longer partner relationships were related to an earlier age of first reproduction which turned out to be the crucial mediator between long-term mating and fitness. In contrast, short-term mating was related to delaying reproduction in Study 1 and a lower number of children in Study 2. We know only one study which measured the number of partners and the time individuals spent in romantic relations (measured as the time spent married) and their relations with reproductive success (Borgerhoff Mulder \& Ross, 2019). Having in mind the huge differences between the examined populations (the previous research was conducted on the Pimbwe tribe in West Tanzania), the similarities between the findings are striking: both studies found that the duration of partner relationship was more beneficial for fitness and that these benefits were more pronounced in males compared to females.

There is another implication of the lack of associations between short-term mating and fitness. Some authors use the scores on sociosexuality (which basically measure the short-term mating tendency) to operationalize "reproductive strategies", although not precisely asserting what strategies these are (Neberich, Penke, Lehnart, \& Asendorpf, 2010). In accordance with this, short-term mating is sometimes used as a proxy of fitness itself (more precisely, as a number of coital acts corrected for a fixed "probability of conception in an absence of contraception") and hence used to estimate the selection on a particular trait (Kordsmeyer, Hunt, Puts, Ostner, \& Penke, 2018). However, the data obtained in the present study clearly show that these assumptions cannot be hold: short-term mating is simply unrelated with fitness, with some indications of negative relations between them. Hence, actual reproductive success should be used to estimate fitness, especially in the light of data that the selection on reproductive success is increased, as opposed to the selection on longevity, in populations which undergo demographic transition (Moorad, 2013). 
We examined Bateman's three coefficients (Bateman, 1948; Arnold \& Duvall, 1994) in order to estimate the presence of sexual selection: variance in mating, reproduction and the association between mating and reproduction. Of course, we should be cautious in the interpretation of variance in mating and fertility: reliable estimations of these parameters should involve representative samples. Our samples were not representative of the Serbian population, although the sample examined in Study 2 had several characteristics of representativeness. Despite this fact, it is interesting to mention that all of the effects detected were in congruence with the sexual selection theory: the variation in mating (observed in Study 1 and 2), reproductive success (Study 2) and the finding of higher associations between mating and reproduction in males compared to females (Study 1 and 2). These findings are in accordance with several previous empirical studies (Brown et al., 2009; Borgerhoff Mulder \& Ross, 2019; Courtiol et al., 2012; Jokela et al., 2010), despite the fact that none one of these studies were conducted in industrial and post-industrial human populations. This is particularly interesting since theory and previous data show that sexual selection is weaker in monogamous, compared to polygamous societies (Moorad et al., 2011). Hence, although probably with low intensity, sexual selection still operates in contemporary humans; more precisely, selection primarily acts to enhance male effort in long-term mating.

\section{2. Can mating patterns indicate life history trajectories?}

Apart from sexual selection, mating patterns could be part of human life history dynamics: correlated traits and events of human reproductive ecology integrated in a fitness maximization process. Due to differences in ecological conditions and individual characteristics, humans (like other species as well) may have different pathways of fitness maximization, which are often labeled as fast and slow (Del Giudice et al., 2015). However, there are two opposite hypotheses of the role that mating patterns play in life history dynamics: one assumes that shortterm mating represents a part of fast life history trajectory (Belsky et al., 1991; Chisholm, 1999), while the other posits the same role for long-term mating (Gangestad \& Simpson, 2000). Both hypotheses have acquired some empirical support but it seems that there are more findings which corroborate the former one (Copping \& Campbell, 2015; Kogan et al., 2015; Lukaszewski, 2015; Chua et al., 2016; Schmitt, 2005). The present data did not provide findings which may unambiguously support either of these hypotheses. However, the present data was more in line with the strategic pluralism theory (Gangestad \& Simpson, 2000). Short term mating showed the signatures of both fast and slow life history while long-term mating exhibited more consistent fast life history dynamics. This is congruent with previously described relations between longterm mating, the age of first reproduction, and reproductive success: elevating reproductive output, especially by early reproduction, is one of the crucial features of a fast life history trajectory.

Why were there no clearer associations between mating and life history? Well, the view of life history as a singular dimension may be an oversimplifying framework for the analysis of human life histories. Recently, several critiques of the slow-fast life history continuum's existence have been published (Stearns \& Rodrigues, 2020; Royauté, Berdal, Garrison, \& Dochtermann, 2018; Zietsch \& Sidari, in press). Furthermore, empirical data showed that the latent space of life history indicators probably cannot be reduced to a single slow-fast dimension, i.e. it is much more complex and consists of several largely unrelated factors (Međedović, 2020a; 2020b). The relations between the parameters of reproductive ecology obtained in the present study (i.e. low 
magnitude correlations with a high number of non-significant correlations) are in contrast to the existence of a clear slow-fast continuum as well.

\section{3. Assessment of dynamic events is needed to explain the link between mating and fitness}

Previous research found a negative correlation between short and long-term mating (Jackson \& Kirkpatrick, 2007), but these two mating patterns were uncorrelated in both studies we have conducted. It seems that short and long-term mating should not be viewed as the opposite poles of a single behavioral dimension. Recent research in the dynamics of romantic bonding showed that short- and long-term mating are indistinguishable in the initial phases of the mating process; furthermore, people initially do not know if they want a short or a long-term relationship (Eastwick, Keneski, Morgan, McDonald, \& Huang, 2018). Hence, short and longterm mating depictions need dynamic descriptions which would posit them as mating processes; by analyzing the temporal dimensions of the mating process we may grasp more complex differences, but similarities as well, between short and long-term mating (Eastwick, Finkel, \& Simpson, 2019). For example, two additional measures would be very useful in our current research: 1) the age participants were when they started their longest relationship - it is highly relevant whether an individual started to form long-term partner relations in adolescence or in their thirties (the latter case would enable an individual to have more short-term relations in adolescence and young adulthood); 2) extra-pair mating - sexual or emotional relations which occurred when an individual was engaged in a relationship - for individuals who report high extra-pair mating we should not expect negative relations between short and long-term mating nor positive correlations between long-term mating and parental investment in the first place.

\section{4. Limitations and future directions}

There are several important limitations of the present research. As we have already mentioned, the samples of participants the data were collected on were not representative, which limits the generalization of the data. The conducted studies were cross-sectional, which is a fact that prevents causal inferences from the data; this is a limitation of previous studies in this topic as well. We did not use objective information about the participants' childhood environment but the estimations of ecological characteristics: future research may analyze objective indicators of environment like mortality rates, characteristics of the healthcare system or childhood environmental instability. Furthermore, parental fitness was not controlled for in the present research; future studies should not only control for parental reproductive success but examine the parental influence on mating in offspring, since there is a parent-offspring conflict regarding the mate choice (Buunk, Park, \& Dubbs, 2008).

\section{5. Concluding remarks}

Mating is one of the central behaviors which influence fitness. However, previous studies on mating were relatively narrow because they explored the topics and followed methodology dominant in two principal fields of evolutionary social scientists: evolutionary psychologists were dominantly interested in the sex differences in mating strategies and neglected real-life reproductive events related to fitness; behavioral ecologists analyzed fitness (and consequently selection) but usually were limited to the number of marriages as a measure of mating. Here we 
tried to integrate these two frameworks in order to obtain a more comprehensive picture of mating in a reproductive ecology of the society in a demographic transition. The findings justified this strategy: they revealed fundamental differences in selection regimes on short and long-term mating; advanced our knowledge on sexual selection in humans, and initiated a new outlook on a life history of mating. The research suggested a potential complementarity of evolutionary psychology and human behavioral ecology which may be used to further advance evolutionary human sciences.

\section{References:}

Arnold, S. J., \& Duvall, D. (1994). Animal mating systems: a synthesis based on selection theory. The American Naturalist, 143(2), 317-348. https://doi.org/10.1086/285606

Bateman, A. J. (1948). Intra-sexual selection in Drosophila. Heredity, 2(3), 349-368.

Belsky, J., Steinberg, L., \& Draper, P. (1991). Childhood experience, interpersonal development, and reproductive strategy: An evolutionary theory of socialization. Child development, 62(4), 647-670. https://doi.org/10.1111/j.1467-8624.1991.tb01558.x

Blurton Jones N. (2016). Demography and evolutionary ecology of Hadza hunter-gatherers. Cambridge University Press: Cambridge.

Bond, N. W. (2005). Who's zooming who? Behavioral and Brain Sciences, 28(2), 278-278. https://doi.org/10.1017/S0140525X05250057

Borgerhoff Mulder, M. (in press). Bateman's principles \& the study of evolutionary demography. In O. Burger, R. Lee, \& R. Sear (Eds.), Human Evolutionary Demography. Retrieved from: https://osf.io/64js5/

Borgerhoff Mulder, M. (2017). Review of Demography and evolutionary ecology of Hadza hunter-gatherers by Nicholas Blurton Jones. Human Nature, 28, 117-127. https://doi.org/10.1007/s12110-016-9280-9

Borgerhoff Mulder, M., \& Ross, C. T. (2019). Unpacking mating success and testing Bateman's principles in a human population. Proceedings of the Royal Society B, 286(1908), 20191516. https://doi.org/10.1098/rspb.2019.1516

Brown, G. R., Laland, K. N., \& Borgerhoff Mulder, M. (2009). Bateman's principles and human sex roles. Trends in Ecology \& Evolution, 24(6), 297-304. https://doi.org/10.1016/j.tree.2009.02.005

Buunk, A. P., Park, J. H., \& Dubbs, S. L. (2008). Parent-offspring conflict in mate preferences. Review of General Psychology, 12(1), 47-62. https://doi.org/10.1037\%2F10892680.12.1.47

Buss, D. M. (2006). Strategies of human mating. Psihologijske teme, 15(2), 239-260. 
Chapais, B. (2013). Monogamy, strongly bonded groups, and the evolution of human social structure. Evolutionary Anthropology: Issues, News, and Reviews, 22(2), 52-65. https://doi.org/10.1002/evan.21345

Chisholm, J. S. (1999). Attachment and time preference: Relations between early stress and sexual behavior in a sample of American university women. Human Nature, 10(1), 51-83. https://doi.org/10.1007/s12110-999-1001-1

Chisholm, J. S., Quinlivan, J. A., Petersen, R. W., \& Coall, D. A. (2005). Early stress predicts age at menarche and first birth, adult attachment, and expected lifespan. Human Nature, 16(3), 233265. https://doi.org/10.1007/s12110-005-1009-0

Chua, K. J., Lukaszewski, A. W., Grant, D. M., \& Sng, O. (2016). Human life history strategies: Calibrated to external or internal cues? Evolutionary Psychology, 15(1), 1474704916677342. https://doi.org/10.1177\%2F1474704916677342

Copping, L. T., \& Campbell, A. (2015). The environment and life history strategies: Neighborhood and individual-level models. Evolution and Human Behavior, 36(3), 182-190. https://doi.org/10.1016/j.evolhumbehav.2014.10.005

Courtiol, A., Pettay, J. E., Jokela, M., Rotkirch, A., \& Lummaa, V. (2012). Natural and sexual selection in a monogamous historical human population. Proceedings of the National Academy of Sciences, 109(21), 8044-8049. https://doi.org/10.1073/pnas.1118174109

Darwin, C. (1871). The descent of man, and selection in relation to sex. Murray: London.

Del Giudice, M., Gangestad, S. W., \& Kaplan, H. S. (2015). Life history theory and evolutionary psychology. In D. M. Buss (Ed.), The handbook of evolutionary psychology-Vol. 1: Foundations (2nd ed., pp. 88-114). New York, NY: John Wiley.

Dunkel, C. S., Mathes, E. W., Kesselring, S. N., Decker, M. L., \& Kelts, D. J. (2015). Parenting influence on the development of life history strategy. Evolution and Human Behavior, 36, 374378. https://doi.org/10.1016/j.evolhumbehav.2015.02.006

Eastwick, P. W., Finkel, E. J., \& Simpson, J. A. (2019). Relationship Trajectories: A MetaTheoretical Framework and Theoretical Applications. Psychological Inquiry, 30(1), 1-28. https://doi.org/10.1080/1047840X.2019.1577072

Eastwick, P. W., Keneski, E., Morgan, T. A., McDonald, M. A., \& Huang, S. A. (2018). What do short-term and long-term relationships look like? Building the relationship coordination and strategic timing (ReCAST) model. Journal of Experimental Psychology: General, 147(5), 747. https://psycnet.apa.org/doi/10.1037/xge0000428 
Gangestad, S. W., \& Simpson, J. A. (2000). The evolution of human mating: Trade-offs and strategic pluralism. Behavioral and brain sciences, 23(4), 573-587. https://doi.org/10.1017/S0140525X0000337X

Gillespie, D. O., Russell, A. F., \& Lummaa, V. (2008). When fecundity does not equal fitness: evidence of an offspring quantity versus quality trade-off in pre-industrial humans. Proceedings of the Royal Society B: Biological Sciences, 275(1635), 713-722. https://doi.org/10.1098/rspb.2007.1000

Griskevicius, V., Delton, A. W., Robertson, T. E., \& Tybur, J. M. (2011). Environmental contingency in life history strategies: the influence of mortality and socioeconomic status on reproductive timing. Journal of personality and social psychology, 100(2), 241-254. https://psycnet.apa.org/doi/10.1037/a0021082

Holtzman, N. S., \& Senne, A. L. (2014). Fast and slow sexual strategies are not opposites: Implications for personality and psychopathology. Psychological Inquiry, 25(3-4), 337-340. https://doi.org/10.1080/1047840X.2014.915708

Jackson, J. J., \& Kirkpatrick, L. A. (2007). The structure and measurement of human mating strategies: Toward a multidimensional model of sociosexuality. Evolution and Human Behavior, 28(6), 382-391. https://doi.org/10.1016/j.evolhumbehav.2007.04.005

Janicke, T., Häderer, I. K., Lajeunesse, M. J., \& Anthes, N. (2016). Darwinian sex roles confirmed across the animal kingdom. Science advances, 2(2), e1500983. doi:10.1126/sciadv.1500983

Jennions, M.D., \& Kokko, H. (2010). Sexual selection. In D. F. Westneat \& C.W. Fox (Eds.) Evolutionary Behavioral Ecology (pp. 343-364). Oxford University Press: Oxford.

Jokela, M., Rotkirch, A., Rickard, I. J., Pettay, J., \& Lummaa, V. (2010). Serial monogamy increases reproductive success in men but not in women. Behavioral Ecology, 21(5), 906-912. https://doi.org/10.1093/beheco/arq078

Kogan, S. M., Cho, J., Simons, L. G., Allen, K. A., Beach, S. R., Simons, R. L., \& Gibbons, F. X. (2015). Pubertal timing and sexual risk behaviors among rural African American male youth: Testing a model based on life history theory. Archives of sexual behavior, 44(3), 609-618. https://doi.org/10.1007/s10508-014-0410-3

Kokko, H., \& Jennions, M. D. (2008). Parental investment, sexual selection and sex ratios. Journal of evolutionary biology,21(4), 919-948. https://doi.org/10.1111/j.14209101.2008.01540.x

Kordsmeyer, T. L., Hunt, J., Puts, D. A., Ostner, J., \& Penke, L. (2018). The relative importance of intra-and intersexual selection on human male sexually dimorphic traits. Evolution and Human Behavior, 39(4), 424-436. https://doi.org/10.1016/j.evolhumbehav.2018.03.008 
Lukaszewski, A. W. (2015). Parental support during childhood predicts life history-related personality variation and social status in young adults. Evolutionary Psychological Science, 1(3), 131-140. https://doi.org/10.1007/s40806-015-0015-7

Marlowe, F. (2000). Paternal investment and the human mating system. Behavioural processes, 51(1-3), 45-61. https://doi.org/10.1016/S0376-6357(00)00118-2

Međedović, J. (2019). Life history in a postconflict society. Human Nature, 30(1), 59-70. https://doi.org/10.1007/s12110-018-09336-y

Međedović, J. (2020a). Human life histories as dynamic networks: using Network Analysis to conceptualize and analyze life history data. Evolutionary Psychological Science, advanced online publication. https://doi.org/10.1007/s40806-020-00252-y

Međedović, J. (2020b). On the incongruence between psychometric and psychosocialbiodemographic measures of life history. Human Nature, 31(3), 341-360.

https://doi.org/10.1007/s12110-020-09377-2

Moorad, J. A. (2013). A demographic transition altered the strength of selection for fitness and age-specific survival and fertility in a 19th century American population. Evolution, 67(6), 16221634. https://doi.org/10.1111/evo.12023

Moorad, J. A., Promislow, D. E., Smith, K. R., \& Wade, M. J. (2011). Mating system change reduces the strength of sexual selection in an American frontier population of the 19th century. Evolution and Human Behavior, 32(2), 147-155.

https://doi.org/10.1016/j.evolhumbehav.2010.10.004

Neberich, W., Penke, L., Lehnart, J., \& Asendorpf, J. B. (2010). Family of origin, age at menarche, and reproductive strategies: A test of four evolutionary-developmental models. European Journal of Developmental Psychology, 7(2), 153-177. https://doi.org/10.1080/17405620801928029

Penke, L., \& Asendorpf, J. B. (2008). Beyond global sociosexual orientations: a more differentiated look at sociosexuality and its effects on courtship and romantic relationships. Journal of personality and social psychology, 95(5), 1113-1135. https://psycnet.apa.org/doi/10.1037/0022-3514.95.5.1113

Royauté, R., Berdal, M. A., Garrison, C. R., \& Dochtermann, N. A. (2018). Paceless life? A meta-analysis of the pace-of-life syndrome hypothesis. Behavioral Ecology and Sociobiology, 72, 64. https://doi.org/10.1007/s00265-018-2472-z

Sanjak, J. S., Sidorenko, J., Robinson, M. R., Thornton, K. R., \& Visscher, P. M. (2018). Evidence of directional and stabilizing selection in contemporary humans. Proceedings of the National Academy of Sciences, 115(1), 151-156. https://doi.org/10.1073/pnas.1707227114 
Schmitt, D. P. (2005). Sociosexuality from Argentina to Zimbabwe: A 48-nation study of sex, culture, and strategies of human mating. Behavioral and Brain Sciences, 28(2), 247-275. https://doi.org/10.1017/S0140525X05000051

Sheppard, P., Pearce, M. S., \& Sear, R. (2016). How does childhood socioeconomic hardship affect reproductive strategy? Pathways of development. American Journal of Human Biology, 28, 356-363. https://doi.org/10.1002/ajhb.22793

Simpson, J. A., \& Gangestad, S. W. (1991). Individual differences in sociosexuality: evidence for convergent and discriminant validity. Journal of personality and social psychology, 60(6), 870883. https://psycnet.apa.org/doi/10.1037/0022-3514.60.6.870

Stearns, S. C., \& Rodrigues, A. M. (2020). On the use of "life history theory" in evolutionary psychology. Evolution and Human Behavior, advance online publication.

https://doi.org/10.1016/j. evolhumbehav.2020.02.001

Stewart-Williams, S., \& Thomas, A. G. (2013). The ape that thought it was a peacock: Does evolutionary psychology exaggerate human sex differences? Psychological Inquiry, 24(3), 137 168. https://doi.org/10.1080/1047840X.2013.804899

Tabatabaie, V., Atzmon, G., Rajpathak, S. N., Freeman, R., Barzilai, N., \& Crandall, J. (2011). Exceptional longevity is associated with decreased reproduction. Aging (Albany NY), 3(12), 1202-1205. doi: https://dx.doi.org/10.18632\%2Faging.100415

Trivers, R. (1972). Parental investment and sexual selection. In B. Campbell (Ed.), Sexual selection and the descent of man (pp. 136-179). Chicago: Aldine-Atherton.

Tropf, F. C., Stulp, G., Barban, N., Visscher, P. M., Yang, J., Snieder, H., \& Mills, M. C. (2015). Human fertility, molecular genetics, and natural selection in modern societies. PloS one, 10(6), e0126821. https://doi.org/10.1371/journal.pone.0126821

Uggla, C., \& Mace, R. (2017). Adult sex ratio and social status predict mating and parenting strategies in Northern Ireland. Philosophical Transactions of the Royal Society B: Biological Sciences, 372(1729), 20160318. https://doi.org/10.1098/rstb.2016.0318

Webster, G. D., Graber, J. A., Gesselman, A. N., Crosier, B. S., \& Schember, T. O. (2014). A life history theory of father absence and menarche: a meta-analysis. Evolutionary Psychology, 12(2), 147470491401200202. https://doi.org/10.1177\%2F147470491401200202

Wilson, M. L., Miller, C. M., \& Crouse, K. N. (2017). Humans as a model species for sexual selection research. Proceedings of the Royal Society B: Biological Sciences, 284(1866), 20171320. https://doi.org/10.1098/rspb.2017.1320

Zietsch, B. P., \& Sidari, M. J. (in press). A critique of life history approaches to human trait covariation. Evolution and Human Behavior. https://doi.org/10.1016/j.evolhumbehav.2019.05.007 
Table 1

Sex differences and correlations between the examined variables

1. Number of sexual partners

\begin{tabular}{rrrr}
$\mathrm{M}(\mathrm{SD})_{\text {males }}$ & $\mathrm{M}(\mathrm{SD})_{\text {females }}$ & $\mathrm{F}$ & $\mathrm{t}$ \\
\hline $11.31(14.02)$ & $6.20(8.85)$ & $26.69^{* *}$ & $-4.26^{* *}$ \\
$4.56(1.38)$ & $3.70(1.36)$ & 0.06 & $-5.84^{* *}$ \\
$60.12(78.85)$ & $68.01(90.65)$ & 0.49 & 0.80 \\
$5.73(1.03)$ & $5.96(0.84)$ & $4.77^{*}$ & $2.38^{*}$ \\
$6.19(2.05)$ & $6.69(1.77)$ & $6.43^{*}$ & $2.49^{*}$ \\
$6.75(2.46)$ & $6.89(2.40)$ & 0.52 & 0.53 \\
$18.04(2.90)$ & $18.04(3.64)$ & 0.02 & -0.02 \\
$0.34(0.71)$ & $0.37(0.72)$ & 0.23 & 0.38 \\
$30.08(4.93)$ & $28.73(5.48)$ & 1.24 & -1.09 \\
$30.96(3.64)$ & $29.05(2.97)$ & 3.57 & $-4.56^{* *}$ \\
$2.62(0.90)$ & $2.45(0.83)$ & 0.78 & -1.74
\end{tabular}

2. Short-term mating

3. Relationship duration

4. Long-term mating

5. Childhood SES

6. Relations in family

7. Age of first sex

8. Reproductive success

9. Observed AFR

10. Planned AFR

$2.62(0.90)$

$2.45(0.83)$

0.78

$-1.74$

Notes: $\mathrm{F}$ - Levene's test for equality of variances; $\mathrm{t}-\mathrm{t}$-test for equality of means; ${ }^{*}-\mathrm{p}<.05 ;{ }^{* *}-\mathrm{p}<.01$ 
Table 2

Correlations between the examined variables

1. Number of sexual partners

\begin{tabular}{rrrrrrrrrrr}
1 & 2 & 3 & 4 & 5 & 6 & 7 & 8 & 9 & 10 & 11 \\
\hline & $.30 * *$ & .04 & .03 & -.03 & -.05 & $-.35^{* *}$ & -.04 & $.23 *$ & -.02 & -.01 \\
$.29 * *$ & & .03 & .01 & $.13 *$ & .02 & $-.11 *$ & -.04 & -.06 & $.14 *$ & -.03 \\
$.12 *$ & -.09 & & .07 & -.06 & .03 & $-.24 * *$ & $.19 * *$ & .03 & -.09 & .04 \\
-.02 & .00 & .01 & & -.05 & -.04 & -.05 & .01 & -.06 & $-.14 * *$ & $.20 * *$ \\
-.08 & $.11 *$ & $-.10 *$ & -.02 & & $.35 * *$ & .05 & -.01 & -.05 & .04 & -.05 \\
-.06 & .02 & .01 & -.03 & $.35 * *$ & & .08 & -.01 & .05 & -.06 & .00 \\
$-.32 * *$ & $-.15 * *$ & $-.14 * *$ & -.05 & .04 & .08 & & -.08 & .04 & .04 & -.05 \\
$.14 * *$ & $-.21 * *$ & $.47 * *$ & -.06 & $-.11 *$ & -.03 & .04 & & $-.32 * *$ & $/$ & .07 \\
$.28 * *$ & .04 & .09 & -.10 & -.09 & .09 & -.02 & $-.25 *$ & & $/$ & -.02 \\
$.17 * *$ & $.17 * *$ & .05 & $-.17 * *$ & -.07 & -.09 & .08 & $/$ & $/$ & & $-.28 * *$ \\
.01 & .02 & .00 & $.19 * *$ & -.06 & .01 & -.07 & -.01 & .05 & $-.24 * *$ & \\
\hline
\end{tabular}

2. Short-term mating

3. Relationship duration

4. Long-term mating

5. Childhood SES

6. Relations in family

7. Age of first sex

8. Reproductive success

9. Observed AFR

10. Planned AFR

$\quad .19 * * \quad-.06$

$\begin{array}{llll}-.07 & -.01 & .05 & -.24 * *\end{array}$

Notes: zero-order correlations are shown below the diagonal; correlations partialized for sex, age, and education are shown above the diagonal; *-p<.05; ** $-\mathrm{p}<.01$ 
Table 3

Interactions between sex and mating in the prediction of reproductive success

\begin{tabular}{lrr}
\hline & $\beta(\mathrm{SE})$ & $\beta(\mathrm{SE})$ \\
\cline { 2 - 3 } Age & $.03(.05)$ & $.03(.05)$ \\
Education & $.73(.00)^{* *}$ & $.73(.00)^{* *}$ \\
Childhood SES & $-.10(.03)^{* *}$ & $-.10(.03)^{* *}$ \\
Relations in family & $.01(.03)$ & $.01(.03)$ \\
Number of sexual partners & $-.01(.03)$ & $-.01(.03)$ \\
Short-term mating & $-.02(.03)$ & $-.03(.03)$ \\
Relationship duration & $-.03(.03)$ & $-.04(.03)$ \\
Long-term mating & $.13(.03)^{* *}$ & $.08(.03)^{*}$ \\
F & $-.00(.02)$ & $0(.02)$ \\
$\mathrm{R}^{2}$ & $77.17 * *$ & \\
Relationship duration $*$ Sex & .66 & $.08(.05)^{*}$ \\
$\Delta \mathrm{F}$ & & $4.71^{*}$ \\
$\Delta \mathrm{R}^{2}$ & & .01 \\
\hline Notes: ${ }^{*}-\mathrm{p}<.05 ; * * \mathrm{p}<.01$ & &
\end{tabular}


Table 4

Sex differences and correlations between the examined variables

\begin{tabular}{|c|c|c|c|c|}
\hline & $\mathrm{M}(\mathrm{SD})_{\text {males }}$ & $\mathrm{M}(\mathrm{SD})_{\text {females }}$ & $\mathrm{F}$ & $\mathrm{t}$ \\
\hline 1. Number of sexual partners & $8.47(9.05)$ & $3.39(4.45)$ & $150.30 * *$ & $-11.10 * *$ \\
\hline 2. Longest relationship & $11.95(12.51)$ & $9.47(8.91)$ & $84.84 * *$ & $-3.56 * *$ \\
\hline 3. Childhood SES & $5.54(2.28)$ & $5.09(2.17)$ & 1.48 & $-3.20 * *$ \\
\hline 4. Relations in family & $3.77(2.37)$ & $3.79(2.39)$ & 0.07 & 0.08 \\
\hline 5. Number of children & $1.37(1.19)$ & $0.93(1.02)$ & $10.66 * *$ & $-6.28 * *$ \\
\hline 6. Number of grandchildren & $0.49(1.33)$ & $0.17(0.67)$ & $76.68 * *$ & $-4.79 * *$ \\
\hline 7. Children with different partners & $0.05(0.23)$ & $0.03(0.16)$ & $23.22 * *$ & $-2.35 *$ \\
\hline 8. Planned age of first reproduction & $33.97(7.70)$ & $31.24(5.58)$ & $15.87 * *$ & $-3.80 * *$ \\
\hline 9. Observed age of first reproduction & $28.20(5.35)$ & $26.82(5.05)$ & 0.06 & $-3.20 * *$ \\
\hline
\end{tabular}


Table 5

Correlations between the examined variables

1. Number of sexual partners

\begin{tabular}{|c|c|c|c|c|c|c|c|c|}
\hline 1 & 2 & 3 & 4 & 5 & 6 & 7 & 8 & 9 \\
\hline & -.03 & -.01 & .02 & $-.10 *$ & -.06 & .05 & .07 & .07 \\
\hline .01 & & .02 & -.03 & $.13 * *$ & $.10 * *$ & .02 & -.00 & $-.10^{*}$ \\
\hline .03 & -.00 & & $.48 * *$ & -.01 & .07 & -.05 & -.05 & .02 \\
\hline .01 & $-.09 * *$ & $.48^{* *}$ & & .03 & .05 & .04 & .01 & -.01 \\
\hline .02 & $.40 * *$ & .01 & -.04 & & $.14 * *$ & $.25 * *$ & I & $-.31 * *$ \\
\hline .04 & $.34 * *$ & $.07 *$ & -.01 & $.38 * *$ & & .05 & .02 & $-.30 * *$ \\
\hline $.08 *$ & $.09 * *$ & -.04 & .03 & $.29 * *$ & $.12 * *$ & & / & $-.13 * *$ \\
\hline $.22 * *$ & $.21 * *$ & -.10 & -.08 & / & .07 & / & & / \\
\hline $.12 * *$ & -.05 & .03 & -.02 & $-.30 * *$ & $-.22 * *$ & $-.13 * *$ & / & \\
\hline
\end{tabular}

2. Longest relationship

3. Childhood SES

4. Relations in family

5. Number of children

6. Number of grandchildren

7. Children with different partners

8. Planned age of first reproduction

9. Observed age of first reproduction

$.12 * *$

$-.05 \quad .03$

Notes: zero-order correlations are shown below the diagonal; correlations partialized for sex, age, and education are shown above the diagonal; *-p $<.05 ; * *$ $\mathrm{p}<.01$ 
Table 6

Interactions between sex and mating in the prediction of reproductive success

Sex

Age

Education

Childhood SES

Relations in family

Number of sexual partners

Longest relationship

Number of children

$\mathrm{F}$

$\mathrm{R}^{2}$

Relationship duration * Sex

$\Delta \mathrm{F}$

Number of children Number of grandchildren

$\Delta \mathrm{R}^{2}$ $\beta$ (SE) $\beta$ (SE)

\begin{tabular}{rrr}
$\beta(\mathrm{SE})$ & $\beta(\mathrm{SE})$ & $\beta(\mathrm{SE})$ \\
\hline $.08(.05)^{* *}$ & $.06(.04)$ & $.06(.04)$ \\
$.49(.00)^{* *}$ & $.35(.00)^{* *}$ & $.35(.00)^{* *}$ \\
$-.09(.02)^{* *}$ & $-.04(.01)$ & $-.04(.01)$ \\
$-.03(.02)$ & $.05(.02)$ & $.04(.02)$ \\
$.04(.03)$ & $.02(.02)$ & $.02(.02)$ \\
$-.09(.03)^{* *}$ & $-.04(.02)$ & $-.04(.03)$ \\
$.13(.03)^{* *}$ & $.09(.02)^{* *}$ & $-.03(.03)$ \\
$/$ & $.13(.03)^{* *}$ & $.13(.04)^{* *}$ \\
$77.87^{* *}$ & $44.36^{* *}$ & \\
0.36 & 0.26 & \\
\hline & & $.15(.04)^{* *}$ \\
& & $11.87^{* *}$ \\
& & .01 \\
\hline
\end{tabular}

Notes: $*-\mathrm{p}<.05 ; * *-\mathrm{p}<.01$ 


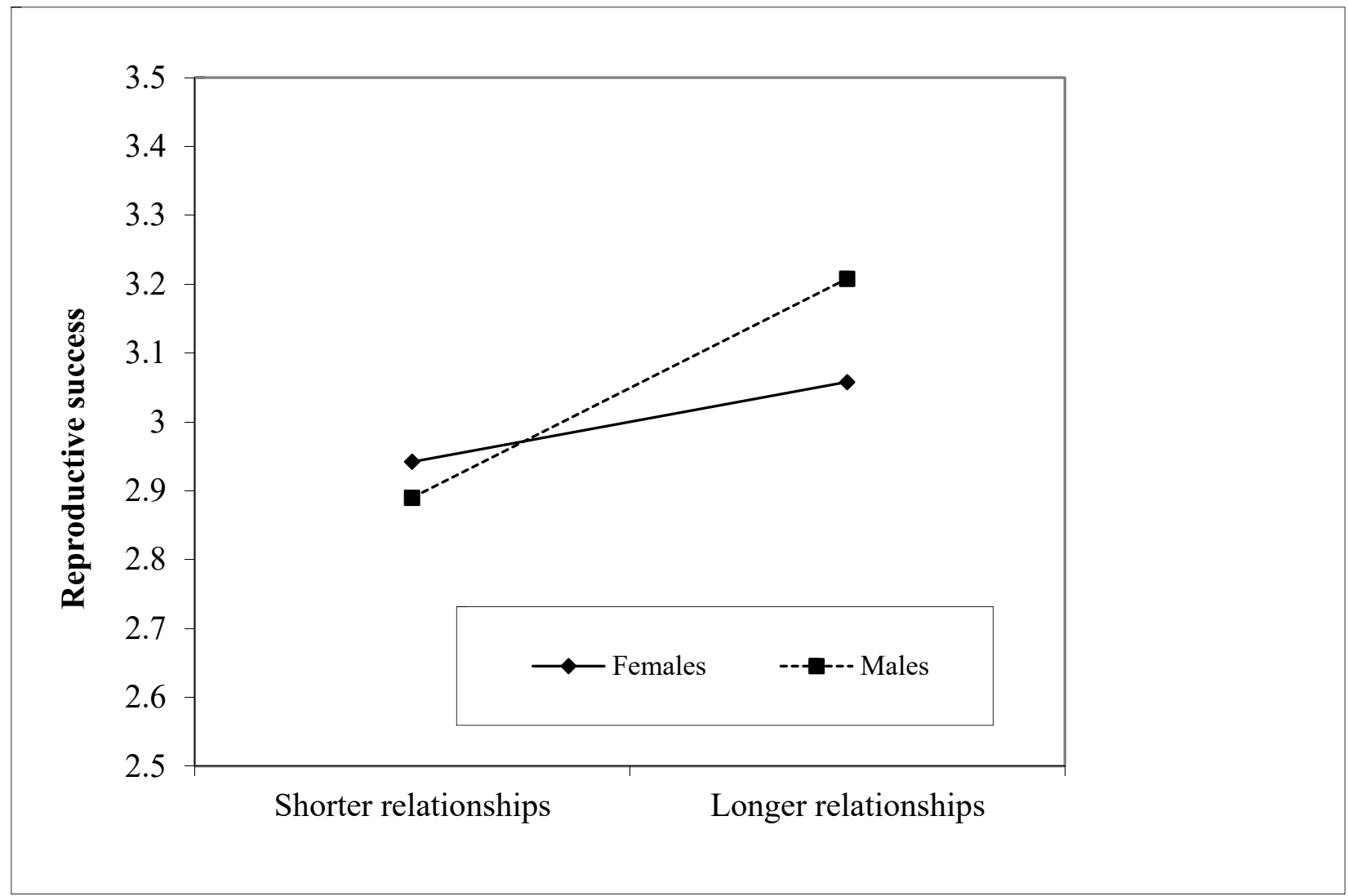

Figure 1

The interaction between sex and Long-term mating in the prediction of reproductive success 


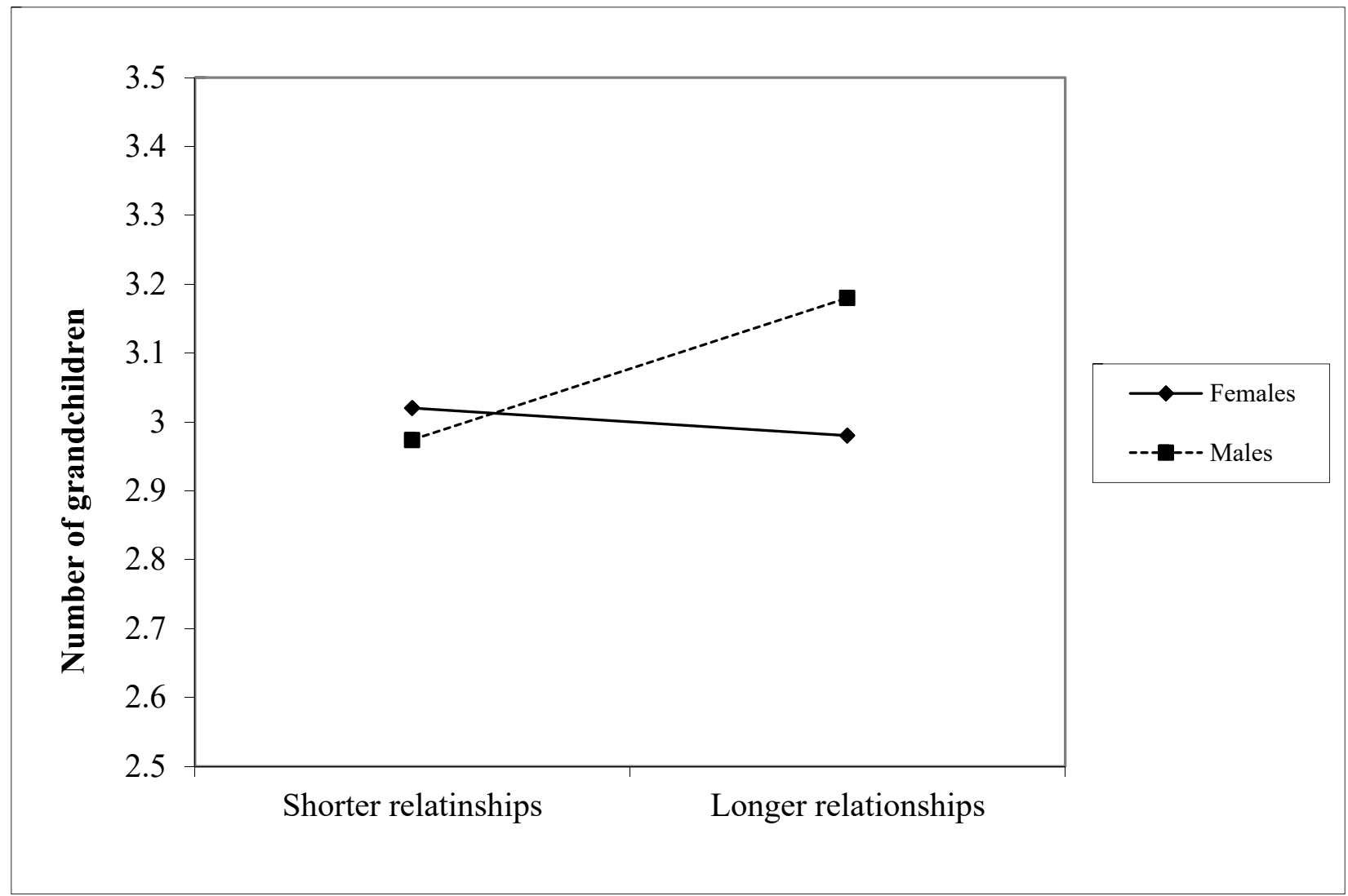

Figure 2

The interaction between sex and Long-term mating in the prediction of Number of grandchildren 


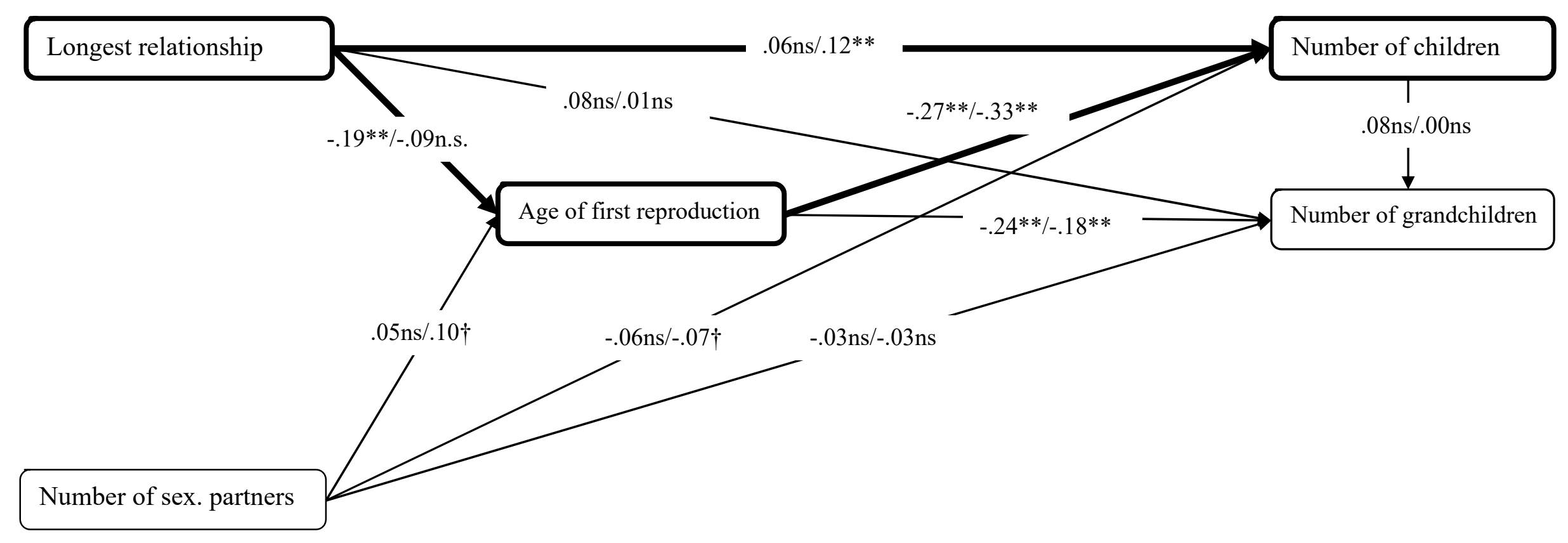

\section{Figure 3}

Path analysis of the Observed age of first reproduction as a mediator between mating and fitness

Notes: standardized coefficients are shown on the diagram; coefficients obtained in the subsample of males are shown first, coefficients obtained in the subsample of females are shown afterwards; key mediation path is shown by the bolded arrows; ns - not significant; $\dagger$ - $\mathrm{p}<.10 ;{ }^{*}$-p $<.05 ; * *-p<.01$ 